\title{
Effect of Temperature on the Level of Corrosion Caused by Heavy Petroleum on AISI 304 and AISI 444 Stainless Steel
}

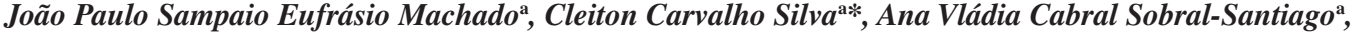 \\ Hosiberto Batista de Sant'Ana ${ }^{\mathrm{b}}$, Jesualdo Pereira Farias ${ }^{\mathrm{a}}$ \\ ${ }^{a}$ Departamento de Engenharia Mecânica e Produção, Campus do Pici, Centro de Tecnologia, \\ Universidade Federal do Ceará, UFC, Bloco 714, 60455-760 Fortaleza - CE, Brazil \\ b Departamento de Engenharia Química, Campus do Pici, Centro de Tecnologia, \\ Universidade Federal do Ceará, UFC, Bloco 709, 60455-760 Fortaleza - CE, Brazil
}

Received: August 23, 2004; Revised: March 29, 2006

\begin{abstract}
This work presents a study on the influence of national heavy petroleum in the corrosion of the AISI 444 and AISI 304 stainless steels in simulated refining operation conditions. The petroleum was first characterized through physicochemical analysis (density, fluidity point, viscosity, sulfur concentration). In an attempt to understand the corrosion effect of temperature and of the type of heating the referred types of steel thermal treatments were carried out at three levels of temperature $\left(200,300\right.$ and $\left.400{ }^{\circ} \mathrm{C}\right)$. The procedure was done in conditions close to those in the distillation column. Heat was gradually increased from room temperature, and directly heated to working temperature. Each treatment took 4 hours to be completed. Scanning electronic microscopy (SEM) and the analysis of $\mathrm{X}$ rays dispersive energy (EDX) were used after the trials to characterize the samples. The results show that treatment temperature, as well as the type of heating, has distinct influences on each type of steel.
\end{abstract}

Keywords: stainless steel, corrosion, and petroleum

\section{Introduction}

The chemical composition of petroleum is highly complex. Petroleum is formed by various hydrocarbons present both in liquid phase (crude oil) and in form of gas, from which are extracted innumerous products: lubricant oil, LPG, gasoline, diesel, kerosene, and a large number of other products that are used as raw material in the petrochemical industry. However, it also presents many others chemical elements in its constitution, such as oxygen, nitrogen, sulfur, heavy metals, chloride, potassium and sodium. These elements may sometimes be considered impurities, being present in the form of sulfurated organic, nitrogenized, oxygenized, and organometalic compounds. Water, mineral salt, and sand are also impurities.

These impurities can give petroleum a high level of corrosiveness, depending on their concentrations $s^{1,2}$. For this reason, the steel used in the manufacturing of equipment to be used in the processing of petroleum is usually covered with material highly resistant to corrosion. The appropriate selection of materials used in refineries is of the utmost importance, not only to guarantee the good functioning of the equipment and the necessary safety to the process, but also to reduce the costs involved ${ }^{3}$.Therefore, the stainless steel is an important class of material used in the manufacturing of components, as well as in coating, since they present an excellent combination of mechanical properties and corrosion resistance ${ }^{4}$.

The idea that petroleum hydrocarbons protect the surfaces of the pipes and the equipments that produce and process petroleum against corrosion is well accepted ${ }^{5,6}$, since a way of protecting metals against corrosion is apply oil and its derivative products (paints and varnish, forming a type of protective layer) on the surface of the pieces and equipment. However, when we refer to the crude oil, this protection is not effective due to the presence of the impurities previously mentioned. According to $\mathrm{Craig}^{7}$, there are three primary corrosive substances in the production of oil and gas: hydrogen sulfide $\left(\mathrm{H}_{2} \mathrm{~S}\right)$, carbon dioxide $\left(\mathrm{CO}_{2}\right)$, and dissolved oxygen $\left(\mathrm{O}_{2}\right)$. These substances when in contact with the surfaces of the materials may initiate a process of corrosion that, either isolated or associated with other factors such as temperature, erosion due to fluid flow, and mechanical efforts, may cause failure in the components or equipments.

For this reason, the equipment used in the refinery industry has to be covered by an internal layer made of high corrosion resistance materials, such as austenitic steel, to resist the severe working conditions. When this cover layer is worn out, an austenitic stainless steel lining is usually applied. The used steels, however, have had crack propagation due to thermal fatigue problems. These problems are caused by the thermal expansion coefficient difference between the austenitic stainless steel and the structure steel.

AISI 304 stainless steels have an excellent corrosion resistance and stress corrosion crack due to the addition of molybdenum, low levels of interstice with carbon and nitrogen, and also addition of titanium and niobium as stabilizer of carbides and nitrates.

Nevertheless, it was not found on the specialized literature studies about AISI 304 stainless steels in the petroleum industry and their behavior due the contact with corrosive substances from the heavy oil. For this reason, it becomes necessary to study the corrosion process in stainless steel used in the manufacturing of equipment for petroliferous industries. In this study we present the results of corrosion in AISI 304 and AISI 444 stainless steel used in petroleum and natural gas processing industrial plants. Initially, these two types of steel were submitted to thermal treatment by immersion in national heavy petroleum, then an evaluation was carried out to analyze the effects of heating and operation temperature on corrosion caused by petroleum and its contaminants. 


\section{Materials and Methodology}

LUBNOR/Petrobras provided the crude oil without any previous processing. It was determined the density, fluidity point, oil viscosity and sulfur indices. The results of these analyses are shown in Table 1.

The samples were submitted to thermal treatment (at three levels of temperature: 200,300 and $400{ }^{\circ} \mathrm{C}$ ) in medium containing national heavy oil, aiming at reproducing the steel severe working conditions in operations in the distillation column. Each experimental run took about 4 hours. The thermal treatments were carried out in the Fuel and Lubricants Laboratory (LCL) of the Chemical Department of the Federal University of Ceará. The trials were carried out partly with the samples being exposed to gradual heating, beginning with room temperature and going up to working temperature, and partly with samples being put straight into the oil heated at the working temperature. The carrying out of these trials aimed at evaluating the effects of heating and of thermal shock on the corrosion of the material. The samples remained in treatment for 4 hours. Then they were taken out for cooling in room temperature. The Table 2 presents a summary of the thermal treatments carried out in this work. The AISI 304 and AISI 444 stainless steel, whose chemical composition is presented in Table 3, was used in the study.

After the trials carried out in high temperature, the samples received a superficial cleaning in toluene and n-pentane. Techniques in scanning electronic microscopy (SEM) and energy dispersive $\mathrm{X}$ ray analysis (EDX) were used for the characterization so as to evaluate

Table 1. Heavy crude oil physic-chemistry analysis.

\begin{tabular}{lc}
\hline \multicolumn{1}{c}{ Physic-chemistry analysis } \\
\hline Density, ${ }^{\circ} \mathrm{API}$ & 14.8 \\
Fluidity point, ${ }^{\circ} \mathrm{C}$ & -3 \\
Oil viscosity $37.8^{\circ} \mathrm{C}, \mathrm{cSt}$ & 8244 \\
Oil viscosity $50.0^{\circ} \mathrm{C}, \mathrm{cSt}$ & 1928 \\
Sulfur indices, $\% \mathrm{~m} / \mathrm{m}$ & 0.79 \\
\hline
\end{tabular}

Table 2. Heat treatment in heave crude oil experiment.

\begin{tabular}{rcl}
\hline Experiment & Steel & Temperature $\left({ }^{\circ} \mathrm{C}\right)$ \\
\hline 1 & AISI 304 & Room temp. -200 \\
2 & AISI 304 & 200 \\
3 & AISI 444 & Room temp. -200 \\
4 & AISI 444 & 200 \\
5 & AISI 304 & Room temp. -300 \\
6 & AISI 304 & 300 \\
7 & AISI 444 & Room temp. -300 \\
8 & AISI 444 & 300 \\
9 & AISI 304 & Room temp. -400 \\
10 & AISI 304 & 400 \\
11 & AISI 444 & Room temp. -400 \\
12 & AISI 444 & 400 \\
\hline
\end{tabular}

the form of corrosion present and the influence of the heavy oil in the samples.

\section{Results and Discussions}

Figure 1a shows the aspect of the AISI 304 stainless steel surface after being thermally treated from room temperature up to $200{ }^{\circ} \mathrm{C}$. Through the seeping of the surface it was possible to detect a preferential attack on the austenite grain boundaries almost completely revealing the microstructure of the material. However, for the sample treated at $200{ }^{\circ} \mathrm{C}$ the attack on austenite grain boundaries was not evident, nevertheless it should noted the presence of oxide precipitates on the surface (Figure 2). In the samples treated from room temperature up to $200{ }^{\circ} \mathrm{C}$ it was possible to observe areas that indicate the occurrence of an initial corrosion process, as well as the presence of dark spots in some areas, which might indicate an initial form of corrosion by pits. This form of corrosion was analyzed by the EDX

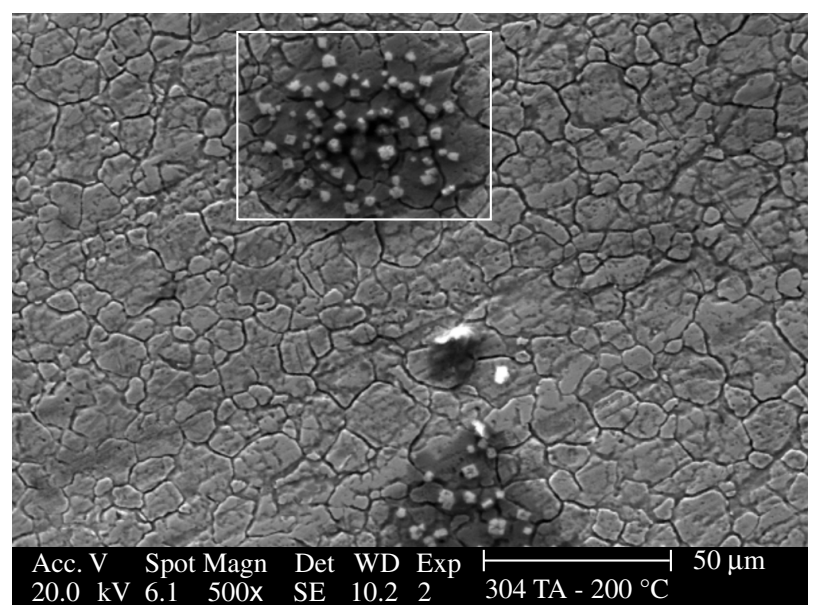

(a)

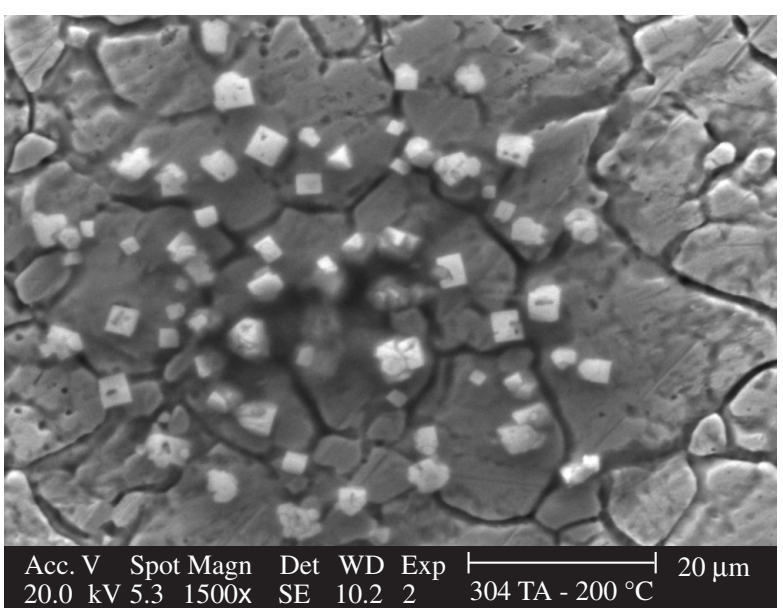

(b)

Figure 1. a) Superficial characterization of the AISI 304 steel, sample heat treated from room temperature up to $200{ }^{\circ} \mathrm{C}$; and b) Enlarged detail of the Figure 1a.

Table 3. Stainless steels chemical composition (\% weight).

\begin{tabular}{|c|c|c|c|c|c|c|c|c|c|c|c|}
\hline Steel & $\mathrm{Si}$ & $\mathrm{Mn}$ & $\mathrm{Ni}$ & $\mathrm{Cu}$ & $\mathrm{Cr}$ & $\mathrm{P}$ & Mo & $\mathrm{Co}$ & $\mathrm{C}$ & $\mathrm{S}$ & $\mathrm{V}$ \\
\hline 304 & 0.41 & 1.38 & 8.10 & 0.09 & 18.09 & 0.02 & 0.03 & 0.07 & 0.03 & 0.002 & 0.04 \\
\hline 444 & 0.38 & 0.16 & 0.18 & 0.04 & 17.46 & 0.02 & 1.70 & 0.02 & 0.01 & 0.002 & 0.05 \\
\hline
\end{tabular}


analysis, through which we identified the points as being focus of corrosion caused by chlorides, present as contaminating element in the national heavy oil. Figure $1 b$ shows the salt precipitates in the form of cubes.

The austenitic stainless steel such as the AISI 304 is not very resistant to corrosion in mediums containing ion chlorides, being then susceptible to corrosion by pits when used in petroleum refining environment. The use of steel with a higher proportion of chrome, nickel and molybdenum is recommended for application in these types of environment, since such elements increase the material corrosion resistance to pits ${ }^{8}$. Figure 3 shows the results of the EDX analysis carried out in the dark area identified in Figure 1. The indication of the presence of chemical elements such as chlorine, sodium, potassium in significant proportions, reinforces the presence of salt on the surface of the steel from the national heavy oil. The presence of peeks of oxygen in the chemical analysis of these areas is indicative of an oxidation process. The results of the chemical analysis of the cubic structure are presented in Figure 4.

Areas with a corrosive aspect were observed on the surface of the AISI 304 stainless steel sample treated at the temperature of $300{ }^{\circ} \mathrm{C}$. Figure 5a shows the aspect of the surface, with both the corroded area and the surface where the impregnation of oil occurred. When amplified, the corroded area presented in Figure 5b shows a structure that is characteristic of oxide grains. EDX analysis was carried out to determine the chemical composition of the structure shown in Figure 5b.

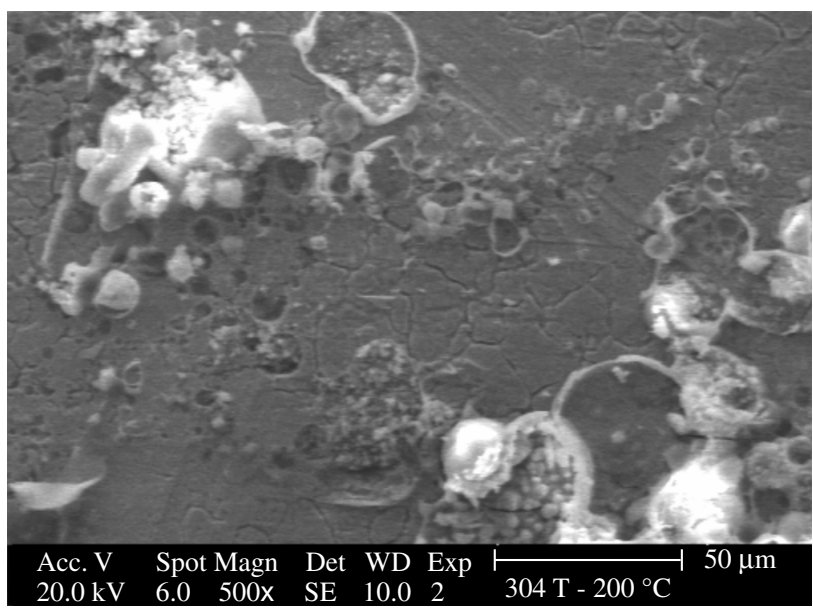

Figure 2. Sample of the AISI 304 steel heat treated in $200{ }^{\circ} \mathrm{C}$.

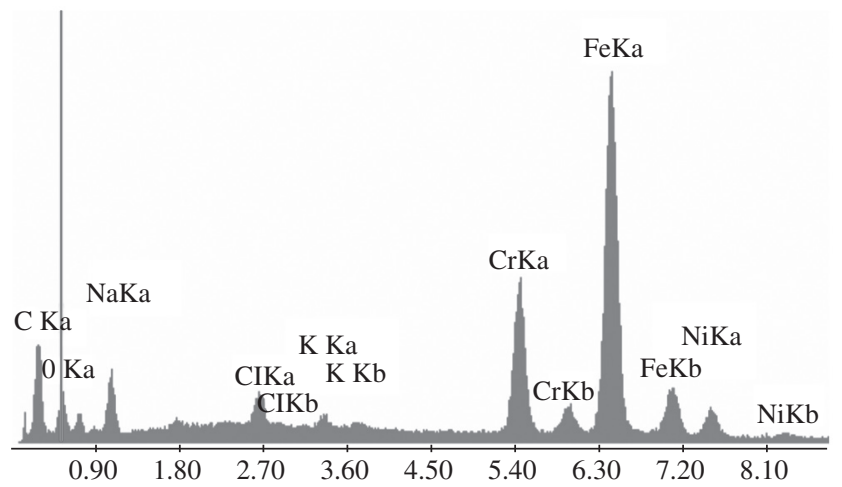

Figure 3. Chemical composition of precipted particles on AISI 304 steel surface obtained by EDX analysis. Sample heat treated from room temperature up to $200{ }^{\circ} \mathrm{C}$.
A large amount of oxygen was observed, as shown in Figure 6, thus proving the suspicions of iron oxide formation, since the iron is the element with the highest concentration in the chemical composition of the stainless steel. Once combined with oxygen, the product of corrosion formed is the oxide iron. Two substances may be responsible for forming this product, the $\mathrm{CO}_{2}$ and the dissolved $\mathrm{O}_{2}$, which are either present in the petroleum, or produced during its processing ${ }^{7,9}$.

Although the sample treated at $300{ }^{\circ} \mathrm{C}$ has presented an initial process of oxidation with the nucleation of oxide grains on the surface of the material, as shown in Figure 5, the austenite grain boundaries

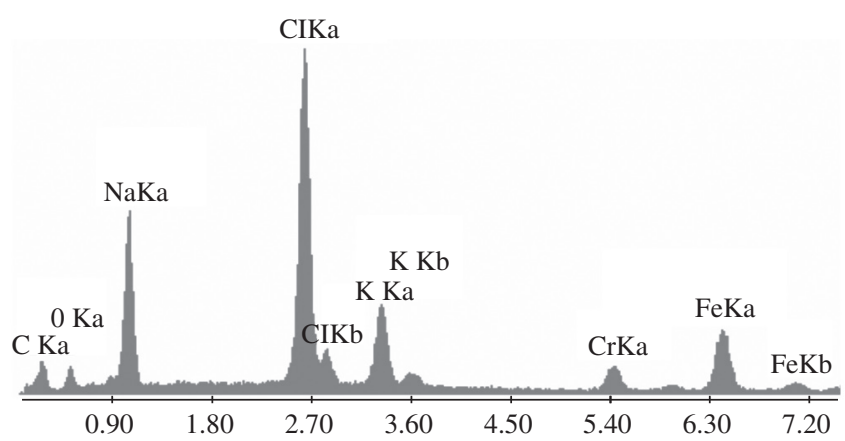

Figure 4. Chemical composition of cubic precipted on surface.

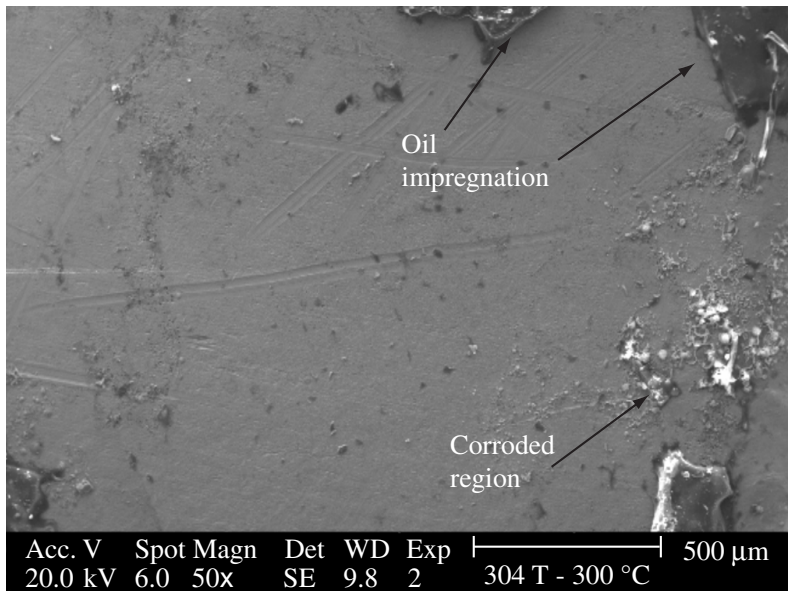

(a)

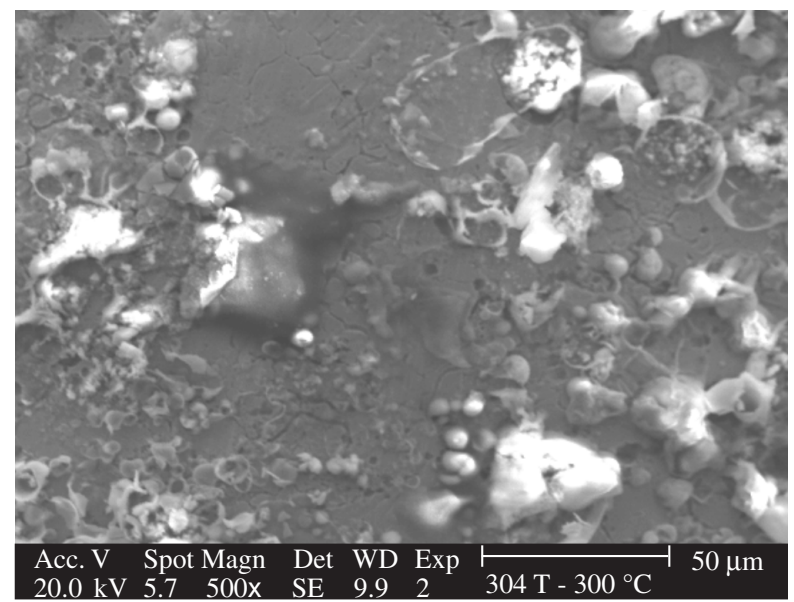

(b)

Figure 5. Scanning electronic microscopy (SEM) a) Surface analysis of AISI 304 steel heat treated at $300{ }^{\circ} \mathrm{C}$; and b) Enlarged detail of the Figure 5a. 
were hardly attacked. On the other hand, for the samples treated with temperatures starting at room temperature and increasing up to $300{ }^{\circ} \mathrm{C}$, the attack on the grain boundaries was as accentuated as the one shown in Figure 1a. This result may be associated to the fact that vapor, gases and acids may be formed during the heating, which in contact with the surface of the steel cause corrosion, preferably on grain boundaries ${ }^{10}$.

The Figure 7 shows the surface of the AISI 304 stainless steel treated thermally at $400{ }^{\circ} \mathrm{C}$. Through the scanning of the steel surface, a kind of uniform corrosion was observed in the entire sample treated, which was characterized by the formation of a layer of oxide on the surface. The cracks present in the oxide layer (Figure 7) are attributed to the differences in the steel and the oxide thermal dilatation coefficients. These cracks are responsible for the continuous exposition of the substrata to the corrosive medium, leading to an intense corrosion in the material. The analysis of the chemical composition obtained by EDX technique (Figure 8) confirms the presence of oxygen and iron. The presence of sulfur in the chemical analysis may be an indication of corrosion caused by acids such as the sulfuric $\left(\mathrm{H}_{2} \mathrm{SO}_{4}\right)$ and sulfide hydrogen $\left(\mathrm{H}_{2} \mathrm{~S}\right)$, which can originate from reactions between the sulfurated compounds and water extracted from the petroleum reservoir. The products of corrosion formed by the activity of the sulfur on iron metals, such as the steel, are normally iron sulfide such as the troilite $(\mathrm{FeS})$, pyrite and macassite $\left(\mathrm{Fe}_{2} \mathrm{~S}\right)^{1}$. These sulfides may be associated to the oxides, forming the layer that covers the steel surface. In both

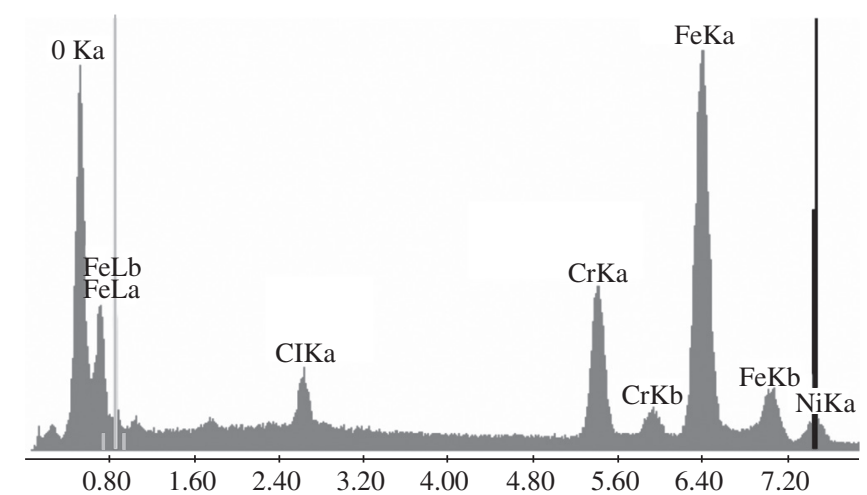

Figura 6. Energy dispersive X ray (EDX) analysis of the AISI 304 steel sample heat treated at $300{ }^{\circ} \mathrm{C}$.

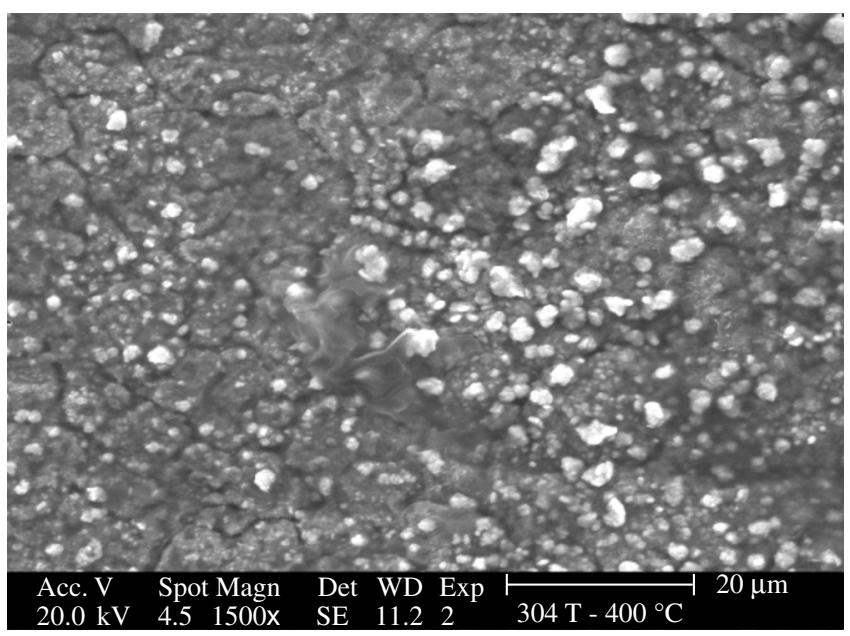

Figura 7. Oxide layer covering AISI 304 steel surface. Sample heat treated at $400{ }^{\circ} \mathrm{C}$. types of corrosion, the loss of mass and the consequent uniform reduction of thickness of the material are expected, being able to reach levels that jeopardize the functioning of the equipment.

In the samples of the AISI 444 ferritic stainless steel treated at $200{ }^{\circ} \mathrm{C}$, with and without heating, no indication of corrosion was observed (Figure 9). The samples treated at $300{ }^{\circ} \mathrm{C}$ showed a thin layer of oxide in some areas. In other areas, these same samples treated at $300{ }^{\circ} \mathrm{C}$, with and without heating beginning at room temperature, showed a more accentuated process of corrosion, with the presence of great oxides and the beginning of an oxide layer such as the one presented in Figure 10.

In the sample heated first at room temperature, then increased up to $300{ }^{\circ} \mathrm{C}$, the formation of a layer of oxide was observed on the surface as mentioned before (Figure 10). The structure of oxide showed in the layer has the typical morphology of a lepidocrocite $(\gamma-\mathrm{FeOOH})$, similar to the one found by Antunes et al. ${ }^{11}$ in his study with carbon steel. This structure is typical of products of initial corrosion, in which, once the exposition and corrosion continue, the lepidocrocite $(\gamma-\mathrm{FeOOH})$ may change into other products such as the goethite $(\alpha-\mathrm{FeOOH})$ and the magnetite $\left(\mathrm{Fe}_{3} \mathrm{O}_{4}\right)$, being the second one more probable to appear in sea water environments ${ }^{11}$.The $\mathrm{X}$ ray dispersive analysis carried out on the layer confirms the formation of the layer of oxide, indicating high peaks of oxygen and iron (Figure 11).

The analysis of the surface of the AISI 444 stainless steel sample treated from room temperature up to the working temperature of

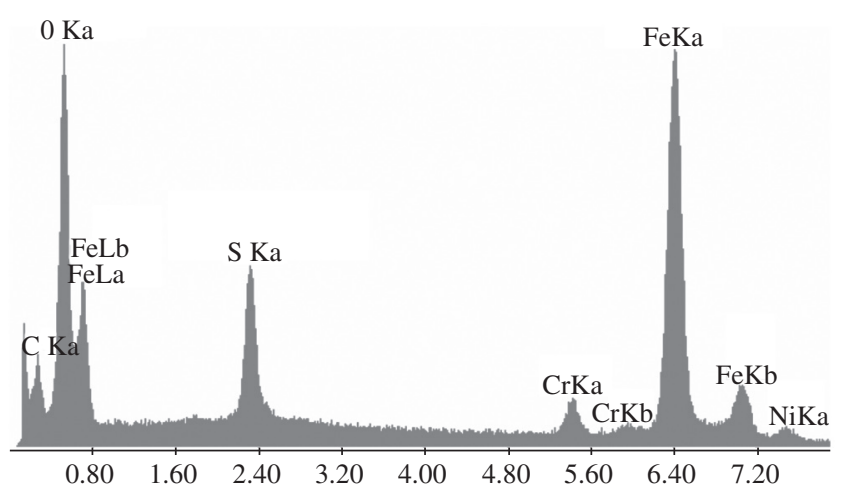

Figura 8. Chemical composition obtained by EDX analysis of the oxide layer formed on AISI 304 steel surface of the sample heat treated at $400{ }^{\circ} \mathrm{C}$.

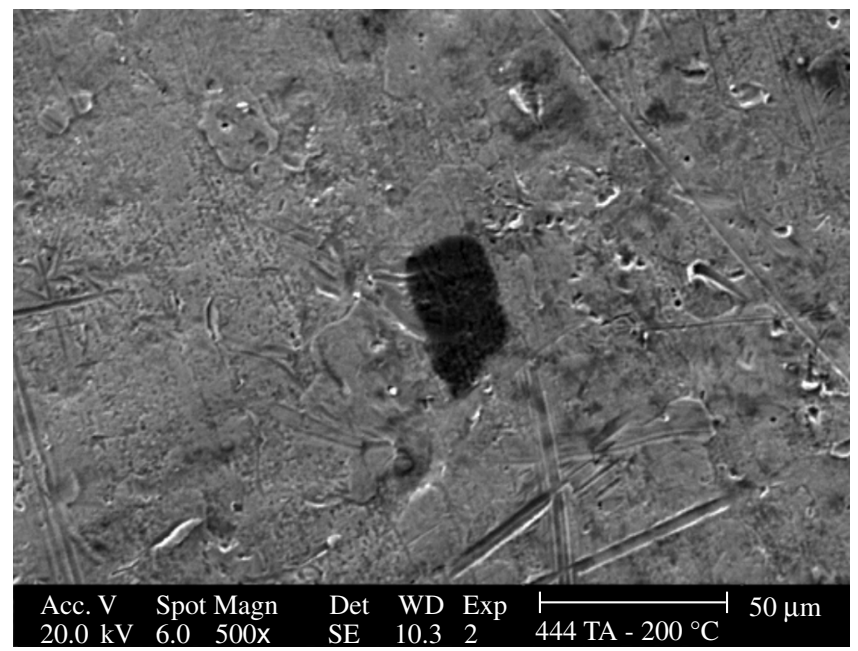

Figure 9. Samples of the AISI 444 ferritic stainless steel treated at $200{ }^{\circ} \mathrm{C}$, no indication of corrosion. 
$400{ }^{\circ} \mathrm{C}$ is shown in Figure 12. Once the scanning of the surface of the material was done it was possible to identify the formation of oxide particles in various areas of the material. The morphology of the oxide particles is a lot different than that of the others found in

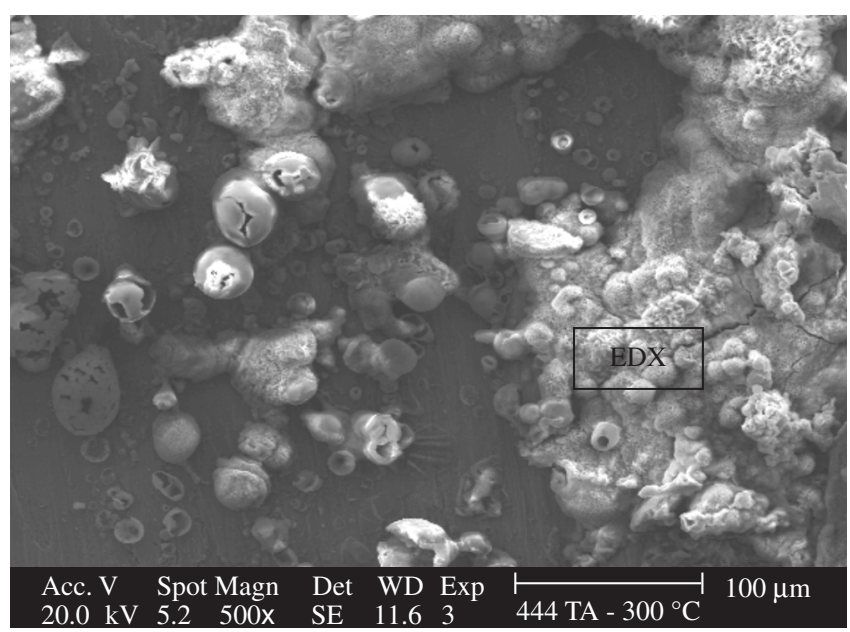

Figura 10. Surface characterization of the AISI 444 stainless steel heat treated at $300{ }^{\circ} \mathrm{C}$. Grain nucleation of iron oxide particles on material surface.

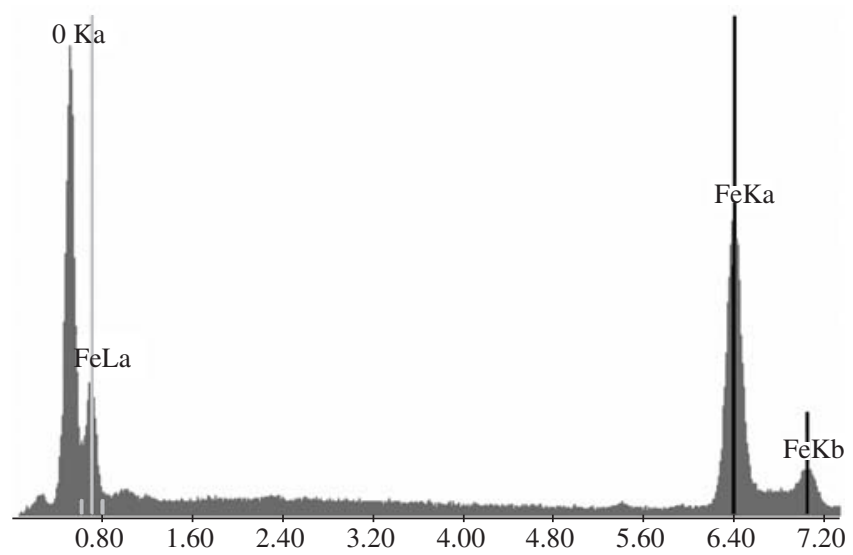

Figura 11. Chemical composition of the region indicated in Figure 10, obtained by EDX analysis.

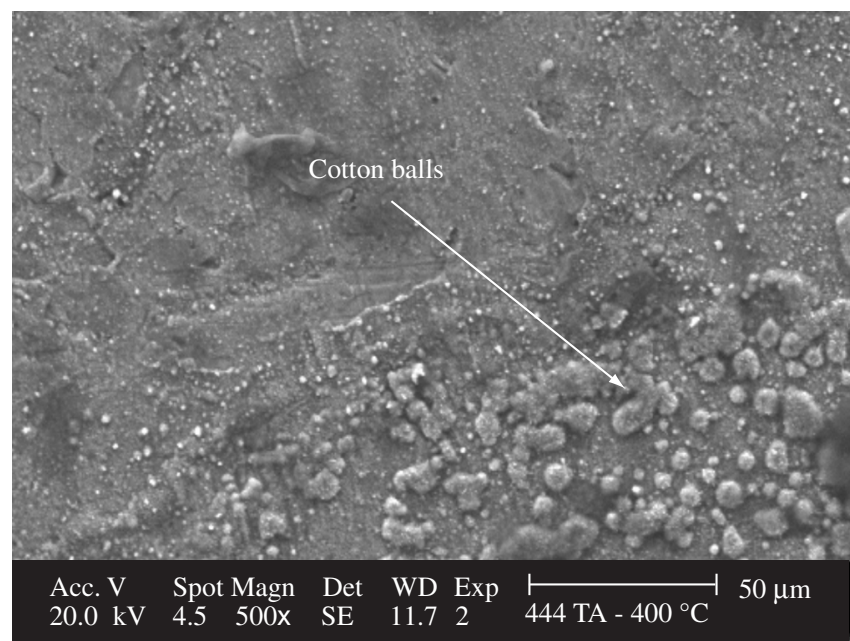

Figura 12. Surface characterization by SEM of AISI 444 stainless steel sample heat treated from room temperature up to $400{ }^{\circ} \mathrm{C}$. this study. Similar structures can be found in the literature, which are named as "cotton ball", typical of the goethite $(\alpha-\mathrm{FeOOH})$. However, other types of analysis are necessary in order to properly classify this product of corrosion, such as $\mathrm{X}$ ray diffraction ${ }^{11,12}$. The analysis of the chemical composition of the structure is shown in Figure 13.

On the whole, the AISI 444 ferritic stainless steel proved to be more resistant to the attack caused by the corrosive activity of the impurities present in the petroleum when compared to the AISI 304 austenitic stainless steel. The highest resistance to corrosion shown by the AISI 444 stainless steel may be associated to the addition of molybdenum which, according the literature, gives the steel a gain in resistance to corrosion, and stress corrosion cracking, depending on the type of environment to which it is exposed ${ }^{10}$. Besides that, its carbon concentration controlled at levels below 0.02 associated to the addition of titanium contributes to stabilize the chrome in solid solution in ferrite through the formation of titanium carbides ${ }^{10}$.

No alterations were observed among the samples treated directly at the working temperature or submitted to the heating of the petroleum beginning at room temperature for the samples of the AISI 444 ferritic stainless steel, constrasting with the results for the AISI 304 austenitic stainless steel, in which the effect of heating is associated to a higher level of corrosion on the austenite grain boundaries. For the AISI 304 austenitic stainless steel, the increase in temperature of treatment had a significant influence on the level of corrosion observed in the material. However, for the AISI 444 ferritic stainless steel this influence was not as effective, since the sample treated at $300{ }^{\circ} \mathrm{C}$ showed to have been more attacked than the sample treated at $400{ }^{\circ} \mathrm{C}$. No sign of corrosion was observed for the samples treated at $200{ }^{\circ} \mathrm{C}$, in the AISI 444 ferritic stainless steel.

\section{Conclusions}

Based on the results presented in this study we have reached the following conclusions:

- For the AISI 304 austenitic stainless steel, the heating of petroleum from room temperature up to the working temperature has significant influence on the type of corrosion, which is characterized by a preferential attack on the austenite grain boundaries;

- For the AISI 304 austenitic stainless steel, the treatment at working temperature, without gradual heating from the room temperature, did not cause any significant attack on the austenite grain boundaries. However, in this situation it is possible to

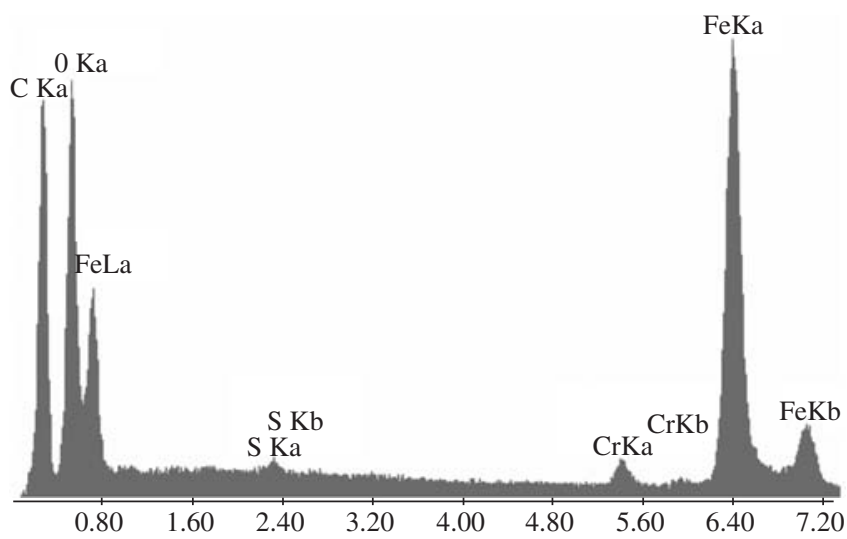

Figura 13. Chemical composition obtained by EDX analysis of the structures indicats in Figure 12. 
occur the corrosion characterized by the nucleation of oxide grains on the surface;

- The working temperature had significant influence on the evolution of corrosion on the AISI 304 austenitic stainless steel, in which was observed an increase on the level of corrosion, following the increase of the temperature of treatment;

- The heating of petroleum from room temperature up to working temperature had no effect on the corrosion of the AISI 444 ferritic stainless steel; and

- The effect of the increase in the working temperature on the corrosion of the AISI 444 stainless steel was not effective, since the most attacked sample was submitted to the treatment at $300{ }^{\circ} \mathrm{C}$

\section{Acknowledgments}

Authors thank to the following laboratories: Engesolda-UFC, LACAM/MEV-UFC and Laboratório de Combustíveis e Lubrificantes (LCL-UFC); also to PETROBRAS, ACESITA and CNPq, FINEP and ANP for their support.

\section{References}

1. Cosultchi A, Garciafigueroa E, Garcia-Borquez A, Reguera E, YeeMadeira H. Petroleum Solid Adherence on Tubing Surface. Fuel. 2001; 80(13):1963-1968.

2. Turnbull A, Griffiths A. Corrosion and Cracking of Weldable 13 wt- $\% \mathrm{Cr}$ Martensitic Stainless Steels for Aplications in the Oil and Gas Industry. Corrosion Engineering, Science and Technology. 2003; 38(1):21-49.
3. Farraro T, Stellina Jr. RM. Materials Construction for Refinery Applications. Proceedings of Corrosion 96, paper n. 614. NACE International; 1996.

4. Folkhard E. Welding Metallurgy of Stainless Steels. revised ed. New York: Spring-Verlag Wien; 1988.

5. Riekels LM, Seetharam RV, Krishnamurthy RM, Kroen CF, Pacheco JL, Hausler RH, Kaczorowski N, Semerad VAW. Manegement of Corrosion in the Arund Field. Corrosion. 1997; 53(1):72-81.

6. Jamaluddin AKM. Deasphalted Oil: a Natural Asphaltene Solvent. SPE Production \& Facilities. 1996; 11(3):161-165.

7. Craig B. Corrosion Products Analyses - A Road Map to Corrosion in Oil and Gas Productions. Materials Perfomance. 2002; 41(8):56-58.

8. Sobral AVC. Estudo da corrosão em aços inoxidáveis sinterizados com revestimentos polimérico. $[\mathrm{PhD}]$. Santa Catarina: Universidade Federal de Santa Catarina; 2000. [In Portuguese].

9. Ikeda A, Ueda M. Predicting $\mathrm{CO}_{2}$ corrosion in the oil and gas industry. revised ed. London: The Institute of Materials; 1994.

10. Sedriks AJ. Corrosion of Stainless Steels. revised ed. New York: Wiley Interscience; 1996.

11. Antunes RA, Costa I, Faria DLA. Characterization of corrosion products formed on steels in the first months of atmospheric exposure. Materials Research. 2003; 6(3):403-408.

12. Raman A, Nasrazadani S, Sharma L. Morphology of Rust Phases Formed on Weathering Steels in Various Laboratory Corrosion Tests. Metallography. 1989; 22(1):79-96. 